\title{
Genetics of Recidivistic Violent Behavior: A Review
}

\author{
M. S Siva Prasad ${ }^{1}$, Jayesh K Joseph², S. P Shaji Prabha ${ }^{3}$, Y Shibu Vardhanan ${ }^{4}$ \\ ${ }^{1,4}$ Department of Zoology, University of Calicut, Calicut University, P.O., Malappuram - 673635, Kerala, India. \\ ${ }^{2}$ Kerala Police Academy, Thrissur - 680631, Kerala, India \\ ${ }^{3}$ Chemical Examiner's Laboratory, Thiruvananthapuram - 695035, Kerala, India
}

\begin{abstract}
Violence is a manifestation of aggression. Aggressive behavior is a personality trait that comprises hostile, threatening and physical violence towards persons and objects. Aggression is a complex behavioral phenotype with a major genetic component. Hence it is reasonable that neural circuitries that affect emotional states like the central serotonergic, dopaminergic and noradrenergic systems also affect the predisposition towards aggressive and antisocial behaviors. Large number of candidate gene studies for aggression has been conducted worldwide. Successful identification of associations between genetic markers and aggression would contribute to understanding the neurobiology of antisocial behavior and potentially provide useful tools for risk prediction and therapeutic targets for high-risk groups of offenders and psychiatric patients.
\end{abstract}

Keywords: Violent behavior, Serotonin, Dopamine, Noradrenaline, Epigenetics.

\section{Introduction}

In criminal justice context recidivism can be defined as the reversion of an individual to criminal behavior after the person has been convicted of a prior offense, sentenced and presumably corrected. The reason for recidivism is the concatenation of failures like failure of the individual to live up to society's expectations, a consequent failure of the individual to stay out of trouble, failure of the individual as an offender, to escape arrest and conviction, failure of the individual as an inmate of a correctional institution to take advantage of correctional programs or failure of the institution to provide programs that rehabilitate.

According to the recent statistics published by National Crime Records Bureau, Ministry of Home Affairs, India, the share of recidivists among all offenders increased to $8.1 \%$ during 2015 as compared to $7.8 \%$ in 2014 . The crime rate, $26.7 \%$, of total violent crimes in the country has shown an increase of $0.3 \%$ during the year $2015^{1}$. The quantum of total violent crimes is continuously increasing from 2010 to 2015.

Criminal recidivism rates remain very high among certain groups of offenders. Many offenders, even after severe sentences of imprisonment, repeatedly fail to desist from crime and reintegrate into the community as law-abiding citizens. Imprisonment, in itself, is incapable of addressing the offender's social integration issues. Even when solid prison programs have helped offenders to achieve some progress during detention, that progress is often lost in some offenders. Here arises the need for addressing the genetic influence of violent behavior of recidivist or habitual offenders.

Violent behavior widely ranges in their seriousness and their impact on the public. Early attempts to explain violent criminal behavior on the basis of inherited genetic predisposition focused on phenotype rather than genotype. In the late nineteenth century, Lombroso attempted to predict criminality based on physical characteristics such as strong jaws, heavy brows, bloodshot eyes, thick lips and projecting ears. Though these characteristics may have correlated to some degree with low intelligence and some are genetic syndromes, they were far from being valid indicators of criminality. Later another researcher, Sheldon also put forth a theory of criminality based on physical characteristics that is mesomorphic or muscular body type as a predictive of criminal behavior. Some research has supported mesomorphy and criminal behavior, but there were no consistent findings. Recently criminal behavior was addressed based on genotype rather than phenotype. Men with an XYY karyotype was once thought to be more aggressive and violent, but this theory was disapproved based on many studies in larger population.

With an understanding of molecular genetics and completion of human genome project, scientists now focuses on multiple genes that code for proteins and enzymes that can influence physiological processes which can in turn predispose an individual towards aggressive behavior which leads to violent crimes.

\section{Genetics of aggressive behavior}

Aggression is a deliberate series of actions that lead to harm, injury or destruction of another organism or property and is the most common factor promoting violent crimes ${ }^{2}$. Beyond the immediate cause of physical injury, aggressive behavior also produces profound long term emotional disabilities in its victims $^{2,3}$. When outburst of aggression is comorbid with DSM-IV- defined neuropsychiatric disorders, the offenders are usually given psychiatric care, but when they appear normal or healthy their most likely fate is punishment by law ${ }^{3}$.

The neural mechanism that mediates aggression is still poorly understood even though several neurotransmitters, neurotransmitter's transporters, neuro-receptors and enzymes are implicated in the pathology of this behavioral trait ${ }^{4}$. Not only the genetic makeup, but environmental factors also

\section{Volume 5 Issue 11, November 2016}




\section{International Journal of Science and Research (IJSR) \\ ISSN (Online): 2319-7064}

Index Copernicus Value (2015): 78.96 | Impact Factor (2015): 6.391

influence the later life predisposition toward violent behaviors ${ }^{4,5,6,7,8,9}$. Most of the genes thought to be related to extreme violence are involved in the detection, transportation, and breaking down of neurotransmitters, especially serotonin and dopamine. There have been many major studies published so far in the area of antisocial behavior and brain chemistry which indicates the role of serotonin, dopamine and nor-epinephrine in the etiology of aggressive and antisocialbehavior ${ }^{4,10}$

\section{An Overview of Major Neurotransmitters Related to Aggressive Behavior}

Neurotransmitters are chemicals stored in the synaptic vesicles of an axon and this axon carries the nerve impulse of the cell body to other neurons. During cellular communication, these chemicals are discharged into the synaptic cleft and are taken up by special receptors in the post synaptic neuron and hence the transmission of information throughout the brain.

There are many different neurotransmitters known to exist in the brain. But a specific neuronal cell will only produce one neurotransmitter. Major neurotransmitters include acetylcholine, the indolamine- serotonin (5-HT) and the catecholamines- dopamine, noradrenaline and adrenaline, all which are classified as monoamines. In addition, amino acid (gama-aminobutryic acid or GABA) and neuropeptides (beta-endorphin and enkephalins) also constitute neurotransmitters. Major neurotransmitters involved in the etiology of aggression and extreme violence are serotonin, dopamine and noradrenaline ${ }^{4,11,12}$.

\subsection{Serotonin}

Serotonin or 5-hydroxytryptamine (5-HT) is a neurotransmitter that has inhibitory properties and act as the body's natural brake system ${ }^{13}$. The release of serotonin modulates behaviors by dampening innate drives and instincts, mainly the impulsive behaviors ${ }^{13,14}$. Serotonin is produced by the raphe nuclei in the middle of the brainstem which send projections through the cerebral hemispheres ${ }^{13,14}$. Serotonin does not cross blood-brain barrier and hence in the brain it is synthesized in the selective cell bodies in the brain stem. The substrate for serotonin synthesis is dietary tryptophan. Tryptophan in plasma passes through the bloodbrain barrier and it is hydroxylated to tryptophan hydroxylase at the $5^{\text {th }}$ position, then decarboxylated by Lamino acid decarboxylase, forming serotonin and stored in vesicles for future release ${ }^{14}$.

Serotonin has been shown to play a key role in the initiation, execution and treatment of aggressive acts ${ }^{14,15,16}$. Several studies have confirmed a negative correlation between serotonin levels in the brain and aggression ${ }^{15,16}$. The negative correlation between serotonin turnover and aggression is commonly known as the serotonin-deficiency hypothesis of aggression $^{15}$. According to this hypothesis, aggression is characterized by low brain 5-HT levels. Given that extreme violence is often unplanned and spontaneous there has been a lot of interest in examining the precise role that the serotonergic system plays in the development of antisocial behaviors $^{17}$

Genes from the serotonergic system have also been identified as being potentially involved in the etiology of extreme violence. The neural activity of serotonergic system depends on the integration of several processes that involve serotonin synthesis, release, reuptake, degradation and receptor activation. The reciprocal interactions of serotonin with other several neurotransmitters and hormones provide further evidence that this indolamine mediates impulsive aggressive behavior. The ultimate effect of serotonin on aggressive behavior appears to be related to its actions on several transmitter substances ${ }^{18}$.

\subsection{Serotonin deficiency and aggression}

The original serotonin deficiency hypothesis was based on a negative correlation between trait like impulsive aggression/violence and the CSF concentration of the 5-HT metabolite in humans and other primates ${ }^{15,19}$. In humans, low levels of the serotonin metabolite, 5-hydroxyindole acetic acid in the cerebrospinal fluid have been associated with aggression and other forms of antisocial behavior including assault, arson, murder, child abuse and as well as in violent forms of suicide ${ }^{15}$. Moreover, a substantial number of nonprimate animal studies have revealed that the propensity to exhibit excessive and abnormal forms of aggression is similarly linked to long-term reduced brain 5-HT activity ${ }^{20}$. In addition, studies have shown that chronically lowering or heightening brain 5-HT provokes increased or reduced levels of aggressive behavior respectively, further supporting the serotonergic deficiency hypothesis of aggressive behavior ${ }^{2,21}$. Initially, the association was found in isolated mice that became aggressive while reducing their 5-HT turnover, an indicator of 5-HT neurotransmission and consequent degradation $^{2,21}$. Similar studies in humans and non-human primates confirm a negative correlation between serotonin turnover and aggressive tendencies ${ }^{20,23}$. A body of research has examined whether variation in serotonin levels corresponds to variation in behavioral problems ${ }^{4}$. Although the findings have been mixed, a relatively recent metaanalysis found a statistically significant and negative association between serotonin levels and extreme violence ${ }^{24}$. In other words, lower levels of serotonin were found to correspond with greater involvement in acts of extreme violence.

Diets which are low in tryptophan, precursor of serotonin which acts to increase its concentrations in the brain, have been shown to increase aggression in animals and humans ${ }^{25}$. The relevance of the serotonergic pathway in violent behavior is further supported by the ability of parachlorophenylalanine, an irreversible inhibitor of 5-HT biosynthesis to heighten aggression in animals ${ }^{26}$.

The extracellular levels of 5-HT also depend on its reuptake and metabolic degradation by monoamine oxidase (MAO) enzymes. Serotonin selective reuptake inhibitors (SSRIs), which increase the availability of serotonin in the brain and are used commonly for the treatment of depression, were also effective for the treatment of aggression ${ }^{27}$. The depletion of MAOA gene in rodents produced an increase in 


\section{International Journal of Science and Research (IJSR) \\ ISSN (Online): 2319-7064}

Index Copernicus Value (2015): 78.96 | Impact Factor (2015): 6.391

aggressiveness $^{28}$. These findings indicate that availability of 5-HT at the synapses influences aggressive behavior. Further, a single nucleotide polymorphism in the coding region of tryptophan hydroxylase, the enzyme for 5-HT synthesis gene, resulted in anger and aggression in healthy humans ${ }^{26}$.

\subsection{Serotonin receptors and aggression}

The effects of serotonin in the nervous system are mediated by a family of different 5-HT receptor subtypes, many of which contain distinct subunits and differ in their mechanism of signal transduction ${ }^{14}$. Although studies have shown inverse relationship between 5-HT levels in the brain and aggressive behavior, the roles of 5-HT receptor subtypes in aggression are yet to be clearly elucidated. Pharmacological investigations and the use of knockout approaches in rodents revealed that $5-\mathrm{HT}_{1}$ and $5-\mathrm{HT}_{2}$ receptors, and their respective sub-types are more relevant in the expression of aggressive behavior $^{26,29}$. The 5-HT $1 \mathrm{~A} / \mathrm{B}$ receptors are located presynaptically as auto receptors on the soma and dendrites of serotonergic neurons, as well as post-synaptically on nonserotonergic neurons in several cortico-limbic areas that receive 5 -HT terminals ${ }^{29}$.

Animal studies have shown that the use of specific agonists especially for $5-\mathrm{HT}_{1}$ receptor subtypes leads to a reduction in aggressive behavior ${ }^{26}$. Conversely, inhibition of $5-\mathrm{HT}_{1}$ receptor subtypes using specific antagonists generally promotes aggression, although this relationship is not very consistent $^{29}$. The $5-\mathrm{HT}_{1 \mathrm{~A} / \mathrm{B}}$ receptors that regulate serotonergic system have shown to be more relevant in the mediation of aggression and violence ${ }^{26,29,30}$. The $5-\mathrm{HT}_{1 \mathrm{~A}}$ agonists exert potent anti-aggressive activity ${ }^{16,26}$, but a number of $5-\mathrm{HT}_{1 \mathrm{~A}}$ antagonists also decreased aggression. Such a discrepancy may be the result of these agents interacting with pre or post-synaptic $5-\mathrm{HT}_{1 \mathrm{~A}}$ receptors, other 5-HT receptor subtypes or other neurotransmitter systems ${ }^{31}$.

Regarding the $5-\mathrm{HT}_{1 \mathrm{~B}}$ receptor, knockout mice lacking this gene display heightened aggression compared to wild types, indicating an important role for this receptor subtype in the mediation of aggression ${ }^{32}$. Activation of $5-\mathrm{HT}_{1 \mathrm{~B}}$ receptors inhibits aggressive behavior despite decreasing serotonergic tone; presumably the behavioral effects of $5-\mathrm{HT}_{1 \mathrm{~B}}$ receptor activation reflect modulation of other neurotransmitter systems ${ }^{26}$. The effect of $5-\mathrm{HT}_{1 \mathrm{~A}}$ and $5-\mathrm{HT}_{1 \mathrm{~B}}$ receptors in the control of 5-HT tone and vice versa aggression suggests that there are other 5 -HT receptors that might be playing a crucial role in violent behavior.

Studies have also shown that there is reduced functionality of post-synaptic $5-\mathrm{HT}_{2 \mathrm{~A} / \mathrm{C}}$ heteroreceptors in aggressive individuals ${ }^{26}$. Studies examining the effect of the $5-\mathrm{HT}_{2}$ receptor reveal that the selective $5-\mathrm{HT}_{2 \mathrm{~A} / 2 \mathrm{C}}$ agonist $1-(2,5-$ dimethoxy-4-iodophenyl)-2-aminopropane decreases aggression at high doses, but also elicits a characteristic side effect of 5-HT stimulation termed "wet dog shaking"33. However, the relationship is not as clear with $5-\mathrm{HT}_{2}$ antagonists, as several studies have shown conflicting results. Antagonism of $5-\mathrm{HT}_{2}$ receptors appears to decrease aggression in animal models, and this effect may explain the ability of newer antipsychotic agents to produce a reduction in aggression and agitation independent of effects on psychotic symptoms ${ }^{34}$. Studies suggest that the overall frequency of assaults, use of seclusion, mechanical restraint and chemical restraint in patients with schizophrenia who are treated with clozapine are reduced over traditional neuroleptics ${ }^{35}$.

The presence of $5-\mathrm{HT}_{3}$ receptors in the amygdaloid complex and cerebral cortex suggests that these receptors may play potential roles in the mediation of aggression ${ }^{27}$. 5-HT receptors are involved in fast excitatory activities that are crucial in emotional and behavioral responses, as well as in other, less defined functions such as sensory perception, memory and motor control ${ }^{36}$. The continued discovery of 5HT receptor subtypes indicates that further study will be needed to clarify the specific roles of the various receptor subtypes and their interactions in aggression.

\subsection{Serotonin transporter and aggression}

The most widely studied serotonergic gene as it relates to behavior is the serotonin transporter (5HTT) gene. The 5HTT gene is located on chromosome 17 and has a 43 basepair insertion/deletion found in the 5 ' regulatory region of the gene $^{37}$. This polymorphism, symbolized as 5HTTLPR, contains two groups of alleles: low expressing alleles and high expressing alleles. The 5HTTLPR polymorphism is functional, where the low expressing alleles have been found to suppress transcription of the serotonin transporter protein $^{38,39}$. The end result is that carriers of the low expressing alleles could have diminished levels of serotonin available in the brain, which has led most researchers to conclude that the low expressing alleles are the risk alleles for antisocial behaviors.

A number of studies have documented a statistically significant association between 5HTTLPR and antisocial outcomes. Carriers of the low expressing alleles are at risk for displaying ADHD symptoms ${ }^{40}$, consuming large amounts of alcohol $^{41}$ and having childhood conduct disorder ${ }^{40}$. Of particular interest are studies that have examined the relation between the 5HTTLPR polymorphism and aggression and violence. There are a limited number of studies that have explored this topic, but there are two showing that the low expressing alleles are associated with increased involvement in aggressive acts in samples of children ${ }^{42,43}$. This is particularly important because one of the best predictors of extreme violence in adolescence and adulthood is childhood aggression and conduct problems ${ }^{44}$. Thus, it is quite possible that the low expressing alleles differentially set persons onto a violent antisocial pathway very early in the life course.

Two additional studies examined the effect that the 5HTTLPR polymorphism has on extreme violence in adults. In the first study, Retz et al., (2004) analyzed the distribution of 5HTTLPR alleles in a sample of violent and nonviolent offenders. Results of their analysis revealed that the low expressing alleles were more prevalent among violent offenders than nonviolent offenders ${ }^{45}$. This is a particularly compelling study because it showed that the 5HTTLPR polymorphism could be used to distinguish different types of offenders. In the second investigation, Liao et al., (2004) also explored the nexus between 5HTTLPR and extreme 


\section{International Journal of Science and Research (IJSR) \\ ISSN (Online): 2319-7064}

Index Copernicus Value (2015): 78.96 | Impact Factor (2015): 6.391

violence $^{46}$. They analyzed genotypic data from a sample of Chinese males. Results of their analysis indicated that extreme violence was more common among males who carried the low expressing alleles. Collectively, these studies hint at the very real possibility that the origins of extreme violence may be partially tied to the 5HTTLPR polymorphism.

\subsection{Dopamine}

Dopaminergic system is part of the pleasure/reward system of the human body and hence dopamine acts as a natural reinforcement of the human body by generating euphoric feelings ${ }^{14}$. That is the reason for repeating the behaviors that stimulates the release of dopamine. The usage of certain drugs (cocaine etc.), eating, sexual intercourse etc., increases dopamine level and hence they are repeated again $^{14}$.

The substrate for serotonin synthesis is dietary phenylalanine. Tyrosine (hydroxyl-phenylalanine) is synthesized from Phenylalanine is found naturally in the breast milk of mammals and tyrosine (hydroxylphenylalanine) is synthesized from Phenylalanine. When tyrosine enters by active transport, it is first converted into dihydroxyphenalanine (DOPA) by the enzyme, tyrosine hydroxylase and then converted into dopamine by the enzyme, L- amino acid decarboxylase (DOPAdecarboxylase). Dopamine is then actively transported into storage vesicles. After dopamine is released into the synaptic cleft, it is removed mainly by re-uptake back into the presynaptic neuron. Dopamine is also removed by the action of the enzyme, catechol-O-methyltransferase (COMT) $)^{14}$.

Dopamine mechanisms associated with the mesolimbic and mesocortical pathways have been linked to various psychiatric disorders such as schizophrenia and anxiety which are thought to be related to increased activity of dopaminergic synapses. The mesocorticolimbic dopaminergic neurons are involved in the mediation of aggressive behavior and also contribute to other motivated behaviors, such as reproductive and maternal behaviors. Variation in dopamine levels has been tied to the development of psychosis, schizophrenia, bulimia and depression. High dopamine levels are associated with involvement in violent and aggressive acts ${ }^{4,47}$

\subsection{Dopamine receptors and aggression}

Two dopamine receptor genes, DRD2 and DRD4 are associated with antisocial behaviors resulting in violence and aggression. DRD2 is located on chromosome 11 and is implicated in the production of D2 receptors, which are involved in the postsynaptic detection of dopamine. D2 receptors are highly concentrated in neurons found in the midbrain, the caudate, the nucleus accumbens, the amygdala, the hippocampus and the cerebral cortex areas of the brain that have been linked to violence and aggression ${ }^{44}$.

DRD2 is a polymorphic gene that contains two alleles: the A1 allele and the A2 allele. Researchers have indicated that carriers of the A1 allele are at an increased risk for various psychopathologies, including victimization ${ }^{48}$, alcoholism ${ }^{49}$ and pathological gambling ${ }^{50}$. The studies examining whether A1 allele is related to extreme violence and aggression are more applicable. A1 allele of DRD2 is associated with increased involvement in acts of serious physical violence and aggression ${ }^{48,51}$.

DRD4 is another dopamine receptor gene that has been identified as a likely contributor to violence and other antisocial behaviors ${ }^{52}$. DRD4 codes for the production of receptors that facilitate postsynaptic detection of dopamine. DRD4 is found on chromosome 11 and has a polymorphism that arises from a 48 basepair VNTR in the third exon. Although the alleles for this polymorphism can be repeated between 2 and 11 times, the 4-repeat allele and the 7-repeat allele are the two most common ${ }^{53}$. This polymorphism has been found to be functional, where the 7-repeat allele codes for receptor proteins that are not as efficient at binding dopamine when compared to the receptor proteins produced by the 4-repeat allele ${ }^{54}$. As a result, the 7-repeat allele has been identified as the risk allele for antisocial behaviors, including extreme violence and physical aggression ${ }^{54}$.

\subsection{Dopamine transporter and aggression}

Dopaminergic gene that has been the widely studied with regard to violence is the dopamine transporter gene (DAT1). DAT1 is located on chromosome 5 and codes for the production of the dopamine transporter protein, which is partially responsible for terminating dopamine activity from the synapse $^{14}$. DAT1 has a polymorphism in the $3^{\prime}$ untranslated region of the gene. This arises from a variable number of tandem repeats (VNTR) that can be repeated between 3 and 11 times and this polymorphism has been shown to affect genetic expression ${ }^{55}$. Some researchers have found out that the 10-repeat allele which is coding for a dopamine transporter protein is extremely efficient at removing dopamine from the synapse ${ }^{56}$. Hence the 10-repeat allele is the "risk allele" that is thought to increase violent, aggressive and various other antisocial behaviors.

Two studies, both of which used data drawn from the National Longitudinal Study of Adolescent Health (Add Health) that document a link between DAT1 10R allele and violence $^{48,51}$. These two researches provide initial evidence that DAT1 may play some role in the commission of extreme violence.

\subsection{Noradrenaline}

Noradrenaline is involved critically in the regulation of mood and behavior. Pharmacological manipulations of noradrenaline levels or specific noradrenergic receptors indicate that noradrenaline signaling facilitates aggression ${ }^{18}$.

The substrate for noradrenaline is also dietary phenylalanine. Synthesis of noradrenaline is same as that of dopamine. After the synthesis and active transport of dopamine into storage vesicles, dopamine is converted into noradrenaline by the enzyme, dopamine-beta-hydoxylase $(\mathrm{DBH})^{14}$. Noradrenaline is then released by exocytosis into the synaptic cleft and is removed primarily by re-uptake into the synaptic terminal. Other mechanism that somewhat contribute include the inactivation by catechol-O-methyltransferase (COMT) in the 


\section{International Journal of Science and Research (IJSR) ISSN (Online): 2319-7064}

Index Copernicus Value (2015): 78.96 | Impact Factor (2015): 6.391

effector cell or by destruction in the liver by COMT and monoamine oxidase (MAO) $)^{14}$.

The greatest concentration of noradrenergic neurons is located within the pons in the locus cerulus. Other groups of noradrenergic neurons are located in different regions of medulla. These neurons project to forebrain, including the limbic system, diencephalon and cerebral cortex ${ }^{14}$.

Noradrenaline's effect on aggressive behavior can be explained in terms of the stress-response system and the type of aggressive behavior elicited ${ }^{57}$. Noradrenaline is affecting aggression on three different levels. The synergetic way of action of noradrenaline is through the hormonal level, the sympathetic autonomous nervous system and the central nervous system ${ }^{18}$. Hormonal catecholamines (adrenaline and noradrenaline) are involved in metabolic preparations of the organism for the prospective fight; the sympathetic system ensures appropriate cardiovascular reaction, while the CNS noradrenergic system prepares the animal for the prospective fight ${ }^{18,58}$. The major indirect effects of noradrenalin on CNS include decrease in pain sensitivity and the enhancement of memory, which is very relevant for the survival of the animal.

Amphetamine usage has also been linked with increased aggression and this is probably because its major action within the brain is to facilitate the release of pro-aggression neurotransmitters such as noradrenaline and dopamine. The $\alpha$ - and $\beta$-adrenergic-receptor sub-types have been shown to mediate aggressive effect of noradrenaline ${ }^{58}$.

\section{Other neurotransmitters associated with aggression}

The other major neurochemicals linked to aggression include gamma-aminobutyricacid (GABA) and glutamate ${ }^{18}$. Agents that affect these neurochemicals are known to cause serious side effects and hence the limitation of their usefulness in aggression $^{59}$.

\subsection{Gamma-aminobutryic acid (GABA)}

In the mammalian central nervous system Gammaaminobutyric acid (GABA) is the primary mediator of inhibitory transmission. GABA modulates aggression and researches have shown low levels of this neurotransmitter in aggressive individuals ${ }^{14}$. Substances that potentiate GABAergic neurotransmission reduce aggressive activity $^{20,59}$. Allosteric modulators of $\mathrm{GABA}_{\mathrm{A}}$ receptors, such as benzodiazepines and barbiturates, influence aggression levels in rodents ${ }^{16,20}$. The facilitative effect of alcohol on aggression occurs through allosteric modulation of $\mathrm{GABA}_{\mathrm{A}}$ receptors. The duration and frequency of opening of chloride ion channels are increased by alcohol and thereby enhances GABA mediated chloride flux. GABA-receptor agonists reduces arousal thereby decreases aggression in many people ${ }^{16,59}$. Drugs such as barbiturates, benzodiazepines and morphine which act on these systems reduce arousal as well as aggression.

\subsection{Glutamate}

Glutamate is an amino acid that has excitatory effect on CNS and hence implicated in the genesis of aggression and violent behavior. Glutamate increases neuronal excitation which increases aggression and is also implicated in the expression of defensive rage behavior in exaggerated emotional reactivity ${ }^{58}$. Compounds with inhibitory effect against glutamate NMDA receptors may exhibit a nonspecific effect on aggression, mainly due to sedation ${ }^{58}$.

\section{Enzymatic Degradation Polymorphisms and Aggression}

Enzymatic polymorphisms that have been involved extreme violence are in the genes that are involved in metabolizing neurotransmitters. Catechol-O-methyltransferase (COMT) gene and the monoamine oxidase $\mathrm{A}$ (MAOA) gene have consistently been shown to relate to antisocial behaviors ${ }^{60}$.

\subsection{Catechol-O-methyltransferase (COMT)}

The COMT gene is located on chromosome 22 and codes for the production of the COMT enzyme. Partial break down of neurotransmitters dopamine, adrenaline and noradrenalineare carried out by this enzyme ${ }^{60}$. Thus it plays a crucial role in terminating the synaptic activity of these neurotransmitters. The COMT gene has a single nucleotide polymorphism which is functional, where one allele codes for the production of the amino acid methionine (Met allele) and the other allele codes for the production of the amino acid valine (Val allele). Val allele is associated with lower COMT activity than the Met allele. COMT activity associated with the Met allele is thought to be positively related to violence and hence the Met allele is the risk allele for antisocial behaviors $^{61}$

Studies in a sample of schizophrenic patients to examine the effect of the COMT polymorphism, patients showing extreme violent behaviors were carrying two copies of the Met allele when compared to patients with no history of extreme violence ${ }^{62}$.

\subsection{Monoamine oxidase- A (MAO-A)}

MAOA is an enzyme that breaks down the neurotransmitters serotonin and dopamine. The MAOA gene codes for the production MAOA enzyme. This gene is located on the $\mathrm{X}$ chromosome. Hence males have only one copy of this gene while females have two copies. The MAOA gene has a polymorphism that is the result of a 30 base-pair VNTR in the promoter region of the gene ${ }^{63,64}$. There have been two categories of alleles for this polymorphism. Alleles that that correspond to low MAOA activity are the first group and the other group contains alleles that correspond to high MAOA activity. The low MAOA activity alleles are not as effective as the high MAOA activity alleles in metabolizing neurotransmitters. Thus the low MAOA activity alleles are considered as the risk alleles for various psychopathologies and extreme violence ${ }^{65}$.

The linkage of MAOA gene to extreme violence in humans was initially discovered by Brunner et al., when they studied

\section{Volume 5 Issue 11, November 2016}




\section{International Journal of Science and Research (IJSR) \\ ISSN (Online): 2319-7064 \\ Index Copernicus Value (2015): 78.96 | Impact Factor (2015): 6.391}

a Dutch kindred ${ }^{66}$. Fourteen males from this family lineage were diagnosed with various mental disorders including serious physical violence. Further studies by Brunner and his colleagues found that females of this family were immune to such behavior and hence they reasoned that the gene would be found on the $\mathrm{X}$ chromosome. By genetic linkage analysis, they found that MAOA gene was malfunctioning in all of the males of these Dutch kindred with this disorder which results in the non-production of MAOA enzyme ${ }^{67}$.

Outside of this single Dutch family pedigree no other documented cases of persons have this mutated MAOA gene $^{68}$. Most of the researches that were conducted to examine whether variants of the MAOA gene are linked to violence revealed that there is not a direct, main association between MAOA and antisocial behaviors. However, there is an impressive amount of research showing that in the presence of detrimental environmental conditions the low MAOA activity alleles can increase violence and aggression. A sample of males from the Dunedin Multidisciplinary Health and Development Study were examined by Caspi et al., (2002) to check the interrelationships among MAOA, childhood maltreatment and antisocial phenotypes. The results indicated that there was no main effect of MAOA on antisocial phenotypes ${ }^{69}$. Capsi and colleagues further analyzed the results and it was revealed that MAOA was associated with aggression and violence in males who had been maltreated as child. Although only about $12 \%$ of the sample had been maltreated and had the low MAOA activity allele, they were responsible for $44 \%$ of all the violent convictions in the cohort ${ }^{69}$. Results of a recent meta-analysis indicated that across a range of studies, the association between MAOA and psychopathology is contingent on the presence of an adverse environment ${ }^{70}$. All the available data suggests that perhaps the one gene that is most consistently related to extreme violence is $\mathrm{MAOA}^{71}$.

\section{Epigenetics}

Epigenetics provides the new science about the interplay of nature and nurture. Epigenetics means in addition to the genes and conceptually it is "any process that alters gene activity without changing the DNA sequence"72. According to Gottlieb (2007) "Epigenetic modifications of DNA affect its ability to be read and translated into proteins by making the code more readily accessible or inaccessible, or they may increase or decrease the level of protein products and thus the reaction range of a gene" ${ }^{, 73}$. DNA itself only specifies for transcription into mRNA and mRNA itself has to be translated by tRNA and assembled by rRNA. In epigenetic modifications depending upon the signals from the internal chemical environment and/or by its external physical and social environment genes are switched on and off according to the challenges it faces ${ }^{74}$.By chronic internal or external environmental events some genes that may be shaped so that they are turned on or off by less than the normal environmental instigation or even in the absence of such instigation. The epigenetics of gene expression may have as much or more influence on developmental individual differences than individual differences in DNA polymorphisms ${ }^{75}$.
The two main processes of epigenetic regulation are DNA methylation and histone acetylation. DNA methylation prevents the translation of DNA into mRNA and hence the particular protein that is coded by a gene is not manufactured. In histone acetylation the DNA wrapped around the histones are loosened, which increases the likelihood of genetic expression ${ }^{76,77}$. In response to various internal and external signals, both processes may occur spontaneously and the resulting regulatory alterations are heritable but reversible ${ }^{77}$. Taken together, the science of epigenetics put forward the new idea of genomic plasticity which is analogous to neural plasticity that makes the brain physically calibrated to environmental events.

From the recent studies of epigenetic molecular mechanisms in the nervous system, epigenetic mechanisms do not just contribute to phenotypic hardwiring at the cellular level. Nervous system is with its abundance of terminally differentiated, non-dividing cells, the neurons. Hence epigenetic mechanisms also plays a role in acute regulation of gene expression in the nervous system in response to a wide range of environmental signals such as stress, physical/sexual abuses, drugs of abuse and many others ${ }^{78}$. In addition, epigenetic mechanisms appear to contribute to both psychiatric and neurological disorders.

Epigenetics in the nervous system, in particular, has made breath-taking advances over the course of the last 10-15 years. Initially, there were only a handful of studies, mainly focused on a single mark, DNA cytosine methylation, in the context of brain aging and development ${ }^{78}$. Fast forward to the present, and the database grew to hundreds of studies, collectively indicating that epigenetic landscapes in brain maintain their highly dynamic and bi-directional regulation throughout the lifespan, and play a critical role in the mechanisms of learning, memory and, more generally, neuronal plasticity ${ }^{78}$. Furthermore, a rapidly expanding repertoire of chromatin modifying drugs has been shown to exhibit an unexpectedly broad therapeutic potential for a wide range of degenerative and functional disorders of the nervous system and furthermore, epigenetic dysregulation at selected loci or even genome wide, is thought to play a key role for the molecular pathology of major psychiatric disorders (including some cases diagnosed with autism, schizophrenia, depression and aggression) or maladaptive mechanisms associated with addiction and substance dependence and abuse ${ }^{74}$.

\section{Conclusion}

Today, in many communities all over the world, violence has become common, resulting in drastic outcomes in society such as an increase in drive by homicides, rapes, gangrelated activities etc.,. Hence more work is needed in understanding genetic and environment underpinnings of aggression and violence. Behavior is the result of a genetic and environment predisposition. Biologic mechanisms of violent behavior can be modified by use of medication. Research from adoption designs suggests that the geneticenvironmental interaction may be a strong contributor to aggressive behavior, that interventions should target individuals who are genetically at risk in addition to living in 


\section{International Journal of Science and Research (IJSR) \\ ISSN (Online): 2319-7064}

Index Copernicus Value (2015): 78.96 | Impact Factor (2015): 6.391

an adverse environment in preference to interventions that focus on only one risk factor.

The genetic-environmental interactions reported here suggest that the expression of a genetic diathesis is dependent on the environment so that reshaping the home environment can have a profound influence on apparently genetically "determined" behavior ${ }^{79}$. Genetic determination is obviously affectable in some cases by the environmental milieu. The molecular genetics findings offer promise of development of biochemical approaches to control or modulation of aggressive behavior. Obviously, the physiology of aggression is complex and, as the review shows, many factors impinge on the biochemical system in the brain. It remains to be seen whether specific biochemical interventions can be devised to affect aggressiveness without causing problems in other behavioral areas. One of the advantages of the molecular biologic approach is the ability to distinguish the effect of a specific gene on the spectrum of aggressive behavior, which people as well as animals manifest. This perspective could result in a biologically based classification of aggressive behaviors that could rationally guide both biochemical and behavioral approaches to aggressiveness management.

Impulsivity, aggressiveness and associated violent behavior are common traits, the expression of which must be carefully modulated to ensure the success of individuals, small groups and large societies, especially within the current framework of globalization. From behavioral genetics, molecular genetics and evolutionary models of violence, we may more fully understand which individuals are at greatest risk of extreme violence. We can then begin to examine the interaction not only between genes and environmental catalysts for violence, but also interaction between genes and treatment and prevention efforts for violence. Even though many genetic and psychological researches related to aggressive behavior have been done worldwide, no such researches among offenders are conducted in India. If the basic causes of the crime can be identified in a grass root level, the corrective measures can be implemented so as to prevent the increasing rate of criminality and recidivism in the country. This is the promise that behavioral genetics and molecular genetics may hold as it's ultimately turns from treatment to outcome research.

\section{Acknowledgement}

The financial support (Junior Research Fellowship) of the University Grants Commission (UGC), India is gratefully acknowledged. This review was a part of the Ph.D Research Programme in the Department of Zoology, University of Calicut, Malappuram, Kerala, India.

\section{References}

[1] Crime in India 2015, National Crimes Records Bureau, Ministry of Home Affairs, New Delhi, India. [Online]. Available: http://ncrb.nic.in/. [Accessed: Nov. 15, 2015].

[2] Weinshenker, N. J., and Siegel, A. (2002). Bimodal classification of aggression: affective defense and predatory attack. Aggress. Violent. Beh., 7 (3), 237-250.
[3] Umukoro, S., Omogbiya, I. A., and Eduviere, T. A (2013). Effect of Jobelyn ${ }^{\circledR}$ on intruder- and isolationinduced aggressive behavior in mice. J. Basic. Clin. Physiol. Pharmacol., 24(4), 263-269.

[4] Raine, A (1993). The Psychopathology of Crime: Criminal Behavior as a Clinical Disorder, Academic Press,USA, pp1- 377. ISBN: 0125761600, 9780125761604.

[5] Blanz, B., Schmidt, M. H., and Esser, G. (1991). Familial adversities and child psychiatric disorders. $J$ Child Psychol Psychiatry, 32 (6), 939-950.

[6] Fergusson, D. M., Horwood, L. J., and Lynskey, M. T. (1996). Childhood sexual abuse and psychiatric disorder in young adulthood: II. Psychiatric outcomes of childhood sexual abuse. J. Am. Acad. Child. Adolesc. Psychiatry, 35 (10), 1365-1374.

[7] Deater-Deckard, K., Dodge, K., Bates, J., and Pettit, G. (1998). Multiple risk factors in the development of externalizing behavior problems: group and individual differences. Dev. Psychopathol., 10 (3), 469-493.

[8] Lahey, B. B.,Loeber, R., Burke, J. D., and Applegate, B. (2005). Predicting future antisocial personality disorder in males from a clinical assessment in childhood. $J$. Consult. Clin. Psychol,. 73(3), 389-99.

[9] Baker, L. A., Raine, A., Liu, J., and Jacobson, K. C. (2008). Differential genetic and environmental influences on reactive and proactive aggression in children. J. Abnorm. Child. Psychol., 36 (8), 1265-1278.

[10] Vassos, E., Collier, D.A. and Fazel, S. (2014). Systematic meta-analyses and field synopsis of genetic association studies of violence and aggression. Mol. Psychiatry, 19: 471-477.

[11] Eichelman, B (1993). Bridges from the animal laboratory to the study of violent or criminal individuals. In S. Hodgins (Ed.), Mental Disorder and Crime, Sage, Newbury Park, CA, USA. pp 194-207.

[12] Schalling, D. (1993). Neurochemical correlates of personality, impulsivity, and disinhibitory suicidality. In S. Hodgins (Ed.), Mental disorder and crime, Sage, Newbury Park, CA, USA. pp 208-226.

[13] Virkkunen, M., and Linnoila, M. (1993). Serotonin in personality disorders with habitual violence and impulsivity. In: S Hodgins (Ed.), Mental Disorder and Crime, Sage, Newbury Park, CA, USA, pp 227-243.

[14] Siegel, A., (2004). The neurobiology of aggression and rage, CRC Press, USA, pp 1-312. ISBN: 0415308348, 9780415308342.

[15]Berman, M. E., Tracy, J. I., and Coccaro, E.F., (1997). The serotonin hypothesis of aggression revisited. Clin. Psychol. Rev., 17 (6), 651-665.

[16] Gowin, J. L., Swann, A. C., Moeller, F. G., Lane, S. D. (2010). Zolmitriptan and human aggression: interaction with alcohol. Psychopharmacology, 210 (4), 521-531.

[17] Gottfredson, M. R., and Hirschi, T. (1990). A general theory of crime, Stanford University Press, USA. pp 1297. ISBN: 0804717737, 9780804717731.

[18] Nelson, R. J., and Trainor, B. C. (2007). Neural mechanisms of aggression. Nat. Rev. Neurosci., 8 (7), 536-546.

[19] Brown, G. L., and Goodwin, F. K. (1986). Cerebrospinal fluid correlates of suicide attempts and aggression. Ann. N. Y. Acad. Sci., 487, 175-188. 


\section{International Journal of Science and Research (IJSR) \\ ISSN (Online): 2319-7064}

Index Copernicus Value (2015): 78.96 | Impact Factor (2015): 6.391

[20] Miczek, K. A., Fish, E. W., and De Bold, J. F., \& de Almeida., R. M. (2002). Social and neural determinants of aggressive behavior: pharmacotherapeutic targets at serotonin, dopamine and $\gamma$-aminobutyric acid systems. Psychopharmacology, 163 (3-4), 434-458.

[21] Blanchard, R. J., Wall, P. M., and Blanchard, D. C. (2003). Problems in the study of rodent aggression. Horm. Behav., 44 (3),161-170.

[22] Garattini, S., Giacalone, E., and Valzelli, L. (1967). Isolation, aggressiveness and brain 5-hydroxytryptamine turnover. J. Pharm. Pharmacol., 19 (5), 338-339.

[23] Brown, G. L., Ebert, M. H., Goyer, P. F., Jimersom, D. C., Klein, W. J., and Bunney W. E., and Goodwin, F. K. (1982). Aggression, suicide and serotonin: Relationships to CSF amine metabolites. Am. J. Psychiatry, 139 (6), 741-746.

[24] Moore, T. M., Scarpa, A., and Raine, A. (2002). A metaanalysis of serotonin metabolite 5-HIAA and antisocial behavior. Aggr. Behav., 28 (4), 299-316.

[25] Cleare, A. J., and Bond, A. J. (1995). The effect of tryptophan depletion and enhancement on subjective and behavioural aggression in normal male subjects. Psychopharmacology, 118 (1), 72-81.

[26] de Boer, S. F., and Koolhaas, J. M. (2005). 5-HT ${ }_{1 \mathrm{~A}}$ and 5- $\mathrm{HT}_{1 \mathrm{~B}}$ receptor agonists and aggression: A pharmacological challenge of the serotonin deficiency hypothesis. Eur. J. Pharmacol., 526 (1-3), 125-139.

[27] Olivier, B., Mos, J., and van der Heyden, J., and Hartog, J. (1989). Serotonergic modulation of social interactions in isolated male mice. Psychopharmacology, 97 (2), 154-156.

[28] Cases, O., Seif, I., Grimsby, J., Gaspar, P., Chen, K., Pournin, S., Muller, U., Aguet, M., Babinet, C., Shih, J. C., et al. (1995). Aggressive behavior and altered amounts of brain serotonin and norepinephrine in mice lacking MAOA. Science, 268 (5218), 1763-1766.

[29] Pineyro, G., and Blier, P. (1999).Autoregulation of serotonin neurons: role in antidepressant drug action. Pharmacol. Rev., 51(3), 533-91.

[30] de Almeida, R. M., and Miczek, K. A. (2002). Aggression escalated by social instigation or by discontinuation of reinforcement ("frustration") in mice: inhibition by anpirtoline - a 5- $\mathrm{HT}_{1 \mathrm{~B}}$ receptor agonist. Neuropsychopharmacology., 27 (2), 171-181.

[31] Sanchez, C., Arnt, J., Hyttel, J., and Moltzen, E. K. (1993). The role of serotonergic mechanisms in inhibition of isolation-induced aggression in male mice. Psychopharmacology, 110 (1-2), 53-59.

[32] Saudou, F., Amara, D. A., Dierich, A., Lemeur, M., Ramboz, S., Segu, L., Buhot, M. C., Hen, R. (1994). Enhanced aggressive behavior in mice lacking 5$\mathrm{HT}_{1 \mathrm{~B}}$ receptor. Science, 265(5180), 1875-1878.

[33] Sloviter, R. S., Drust, E. G., and Connor, J. D. (1978). Specificity of a rat behavioral model for serotonin receptor activation. J. Pharmacol. Exp. Ther., 206 (2), 339-347.

[34] Buckley, P.F., Ibrahim, Z. Y., Singer, B., Orr, B., Donenwirth, K., and Brar, P. S. (1997). Aggression and schizophrenia: Efficacy of risperidone. J. Am. Acad. Psychiatry. Law, 25 (2), 173-181.

[35] Ratey. J., Sovner, R., Parks, A., and Rogentine, K. (1991). Buspirone treatment of aggression and anxiety in mentally retarded patients: a multiple-baseline, placebo lead-in study. J. Clin. Psychiatry, 52 (4), 159162.

[36] Tecott, L. H., Maricq, A. V., Julius, D. (1993). Nervous system distribution of the serotonin $5-\mathrm{HT}_{3}$ receptor mRNA. Proc. Natl. Acad. Sci., 90 (4), 1430-1434.

[37] Heils, A., Teufel, A., Petri, S., Stober, G., Riederer, P., Bengel, D., Lesch, K. P. (1996). Allelic variation of human serotonin transporter gene expression. $J$. Neurochem., 66 (6), 2621-2624.

[38] Lesch, K.P., Bengel, D., Heils, A., Sabol, S. Z., Greenberg, B. D., Petri, S., Benjamin, J., Muller, C. R., Hamer, D. H., and Murphy, D. L. (1996). Association of anxiety related traits with polymorphism in the serotonin transporter gene regulatory region. Science, 274 (5292), 1527-1531.

[39]Hu, X.Z., Lipsky, R. H., Zhu, G., Akhtar L. A., Taubman, J., Greenberg, B. D., et al. (2006). Serotonin transporter promoter gain-of-function genotypes are linked to obsessive-compulsive disorder. Am. J. Hum. Genet., 78 (5) 815-826.

[40] Cadoret, R.J., Langbehn, D., Caspers, K., Troughton, E.P., Yucuis, R \&Sandhu, H. K., and Philibert, R. (2003). Associations of the serotonin transporter promoter polymorphism with aggressivity, attention deficit and conduct disorder in an adoptee population. Compr. Psychiatry, 44 (2), 88-101.

[41] Herman, A. I., Philbeck, J. W., N.L. Vasilopoulos, N. L., and Depetrillo, P. D. (2003). Serotonin transporter polymorphism and differences in alcohol consumption behaviour in a college student population. Alcohol. Alcohol, 38 (5), 446-449.

[42] Beitchman, J. H., Baldassarra, L., Mik, H., De Luca, V., King, N., and Bender, D. (2006). Serotonin transporter polymorphisms and persistent, pervasive childhood aggression. Am. J. Psychiatry, 163 (6), 1103-1105.

[43] Haberstick, B.C., Smolen, A., and Hewitt, J. K. (2006). Family based association test of the 5HTTLPR and aggressive behavior in a general population sample of children. Biol. Psychiatry., 59 (9), 836-843.

[44] Wright, J., Beaver, K., Delisi, M., and Vaughn, M. (2008). Evidence of negligible parenting influences on Self-control, Delinquent peers, and Delinquency in a Sample of Twins. Justice. Quarterly, 25 (3), 544-569.

[45] Retz, W., Retz-Junginger. P., Supprian, T., Thome, J., and Rosler, M. (2004). Association of serotonin transporter promoter gene polymorphism with violence: relation with personality disorders, impulsivity and childhood ADHD psychopathology. Behav. Sci. Law., 22 (3), 415-425.

[46] Liao, D.L., Hong, C. J., Shih, H. J., and Tsai, S. J. (2004). Possible association between serotonin transporter promoter region polymorphism and extremely violent crime in Chinese males. Neuropsychobiology, 50 (4), 284-287.

[47] Niehoff, D (1999). The biology of violence: How understanding the brain, behavior, and environment can break the vicious circle of aggression, The Free Press, New York, pp 1-353. ISBN: 0684831325 9780684831329.

[48] Beaver, K. M.,Wright, J. P., DeLisi, M.,Walsh, A., Vaughn, M. G., Boisvert, D., and Vaske, J. (2007). A gene $\times$ gene interaction between DRD2 and DRD4 is 


\section{International Journal of Science and Research (IJSR) \\ ISSN (Online): 2319-7064}

Index Copernicus Value (2015): 78.96 | Impact Factor (2015): 6.391

associated with conduct disorder and antisocial behavior in males. Behav. Brain. Funct., 3 (30).

[49] Connor, J. P., Young, R., Lawford, B. R., Ritchie, T. L., and Noble, E. P. (2002). D2 dopamine receptor (DRD2) polymorphism is associated with severity of alcohol dependence. Eur. Psychiatry, 17 (1), 17-23.

[50] Comings, D.E., Gade-Andavolu, R., Gonzalez, N., Wu, S., Muhleman, D., Chen, C., Koh, P., Farwell, K., Blake, H., Dietz, G., MacMurray, J. P., Lesieur, H. R., Rugle, and L. J., Rosenthal, R. J. (2001). The additive effect of neurotransmitter genes in pathological gambling. Clin. Genet., 60 (2), 107-116.

[51]Guo, G., Roettger,M. E., and Shih, J. C. (2007). Contributions of the DAT1 and DRD2 genes to serious and violence delinquency among adolescents and young adults. Hum. Genet., 121 (1), 125-136.

[52] Rowe, D. C (2002). Biology and crime, Roxbury, USA, pp 1-161. ISBN: 1891487809, 9781891487804.

[53] Wang, E., Ding, Y.C., Flodman, J. R., Kidd, J. R., Kidd, K. K., Grady, D. L., et al. (2004). The genetic architecture of selection at the human dopamine receptor D4 (DRD4) gene locus. Am. J. of Hum. Genet., 74 (5), 931-944.

[54] Kluger, A. N., Siegfried, Z., and Ebstein, R. P. (2002). A meta-analysis of the association between DRD4 polymorphism and novelty seeking. Mol. Psychiatry, 7 (7), 712-717.

[55] Fuke, S., Suo, S., Takahashi, N., Koike, H., Sasagawa, N., and Ishiura, S. (2001). The VNTR polymorphism of the human dopamine transporter (DAT1) gene affects gene expression. Pharmacogenomics. J., 1 (2), 152-156.

[56] Swanson, J. M., Flodman, P., Kennedy, J., Spence, M. A., Moyzis, R., Schuck, S., et al. (2000). Dopamine genes and ADHD. Neurosci. Biobehav. Rev., 24 (1), 21-25.

[57] Koolhaas, J. M., Korte, S. M., de Boer, S. F., van der Vegt, B. J., van Reenen, C. G., Hopster, H., de Jong, I. C., Ruis, M. A. and Blokhuis, H. J. (1999). Coping styles in animals: current status in behavior and stressphysiology. Neurosci. Biobehav. Rev., 23 (7), 925 -935.

[58] Haller, J., Abraham, I., Zelena, D., Juhasz, G., Makara, G. B., and Kruk, M. R. (1998). Aggressive experience affects the sensitivity of neurons towards pharmacological treatment in the hypothalamic attack area. Behav. Pharmacol., 9(5-6), 469-475.

[59] de Almeida, R. M., Giovenardi, M., da Silva, S. P., de Oliveira, V. P., Stein, D. J. (2005). Maternal aggression in Wistar rats: effect of $5-\mathrm{HT}_{2 \mathrm{~A} / 2 \mathrm{C}}$ receptor agonist and antagonist microinjected into the dorsal periaqueductal gray matter and medial septum. Braz. J. Med. Biol. Res., 38 (4), 597-602.

[60] Volavka, J., Bilder, R., \& Nolan, K. (2004). Catecholamines and aggression: The role of COMT and MAO polymorphisms. Ann. N. Y. Acad. Sci., 1036, 393-398.

[61] Rujesco, D., Giegling, I., Gietl, A., Hartmann, A. M., and Moller, H. J. (2003). A functional single nucleotide polymorphism (V158M) in the COMT gene is associated with aggressive personality traits. Biol. Psychiatry, 54 (1), 34-39.

[62] Lachman, H. M., Nolan, K. A., Mohr, P., Saito, T., and Volavka, J. (1998). Association between catechol Omethyltransferase genotype and violence in schizophrenia and schizoaffective disorder. Am. J. Psychiatry, 155 (6), 835-837.

[63] Sabol, S.Z., Hu, S., and Hamer, D. (1998). A functional polymorphism in the monoamine oxidase $\mathrm{A}$ gene promoter. Hum. Genet., 103 (3), 273-279.

[64] Buckholtz, J.W., and Meyer-Linderberg, A. (2008). MAOA and neurogenetic architecture of human aggression. Trends. Neurosci., 31 (3), 120-129.

[65] Alia-Klein, N., Goldstein, R.Z., Kriplani, A., Logan, J., Tomasi, D.,Williams, B., Telang, F., Shumay, E., Biegon, A., Craig, I. W., Henn, F.,Wang, G. T., Volkow, N. D., and Fowler, J. S. (2008). Brain monoamine oxidase A activity predicts trait aggression. J. Neurosci., 28 (19), 5099-5104.

[66] Brunner, H.G., Nelen, M., Breakfield, X. O., Ropers, H. H., and van Oost, B. A. (1993). Abnormal behavior associated with a point mutation in the structural gene for monoamine oxidase A. Science, 262 (5133), 578580.

[67] Brunner, H. G., Nelen, M. R., van Zandvoort, P., Abeling, N. G., van Gennip, A. H., Wolters, E. C., Kuiper, M. A., Ropers, H. H., and van Oost, B. A. (1993). X-linked borderline mental retardation with prominent behavioral disturbance: Phenotype, genetic localization, and evidence for disturbed monoamine metabolism. Am. J. Hum. Genet., 52 (6), 1032-1039.

[68] Mejia, J. M., Ervin, F. R., Palmour, R. M., and Tremblay, R. E. (2001). Aggressive behavior and Brunner syndrome: No evidence for the C936T mutation in a population sample. Am. J. Med. Genet., 105 (4), 396-397.

[69] Capsi, A., McClay, J., Moffitt, T. E., Mill, J., Martin, J., Craig, I. W., Taylor, A., and Poulton, R. (2002). Role of genotype in the cycle of violence in maltreated children. Science, 297 (5582), 851-854.

[70] Kim- Cohen, J., Caspi, A., Taylor, A., Williams, B., Newcombe, R., Craig, I.W., Moffitt, T. E. (2006). MAOA, maltreatment, and gene-environment interaction predicting children's mental health: New evidence and a meta- analysis. Mol. Psychiatry, 11 (10), 903-913.

[71] Ferguson, C., and Beaver, K. M., (2009). Natural born killers: the genetic origin of extreme violence. Aggress. Violent. Behav., 14(5), 286-294.

[72] Weinhold, B. (2006). Epigenetics: The Science of Change. Environ. Health. Perspect., 114(3), A160 A167.

[73] Gottlieb, G. (2007). Probabilistic epigenesis. Dev. Sci., 10 (1), 1-11.

[74] Landecker, H. and Panofsky, A. (2013). From social structure to gene regulation, and back: A critical introduction to environmental epigenetics for sociology. Annu. Rev. Sociol., 39, 333-357.

[75] Kramer, D.A (2005). Commentary: Gene-environment interplay in the context of genetics, epigenetics, and gene expression. J. Am. Acad. Child. Adolesc. Psychiatry, 44(1), 19-27.

[76] Corwin, E. (2004). The concept of epigenetics and its role in the development of cardiovasculardisease. Biol. Res. Nurs., 6 (1), 11-16.

[77] Rangel, E. L., and Lewis, M. E. (2006). Loud and clear evidence for gene silencing by epigenetic mechanisms in 


\section{International Journal of Science and Research (IJSR) \\ ISSN (Online): 2319-7064}

Index Copernicus Value (2015): 78.96 | Impact Factor (2015): 6.391

autism spectrum and related neurodevelopmental disorders.Clin. Genet., 69 (1), 21-22.

[78] Nestler, E.J. (2012). Epigenetics: Stress makes its molecular mark. Nature, 490 (7419), 171-172.

[79] Beaver, K. M., Wright, J. P., DeLisi, M., Daigle, L. E., Swatt, M. L., and Gibson, C. L. (2007). Evidence of a gene $x$ environment interaction in the creation of victimization: Results from a longitudinal sample of adolescents. Int. J. Offender. Ther. Comp. Criminol., 51 (6), 620-645.

\section{Authors Profile}

Siva Prasad M.S received the B.Sc degree in Medical Microbiology from Centre for Health Sciences, University of Calicut, Kerala, India (2009) and M.Sc degrees in Forensic Science from LNJN National Institute of Criminology \& Forensic Science, Ministry of Home Affairs, New Delhi, India (2012). He has qualified the National Eligibility Test- Junior Research Fellowship (NET-JRF) examination conducted by University Grants Commission, India during the year 2011. He is now doing Ph.D research in the area of behavioral science in the Department of Zoology, University of Calicut, Kerala, India.

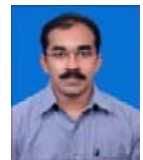

Dr. Y. Shibu Vardhanan, Presently working as Associate Professor \& Co-ordinator UGC-SAP Department of Zoology, University of Calicut, Malappuram Kerala PIN: 673635. Currently focused on Geometric Morphometrics, toxicology and behavioral science. 